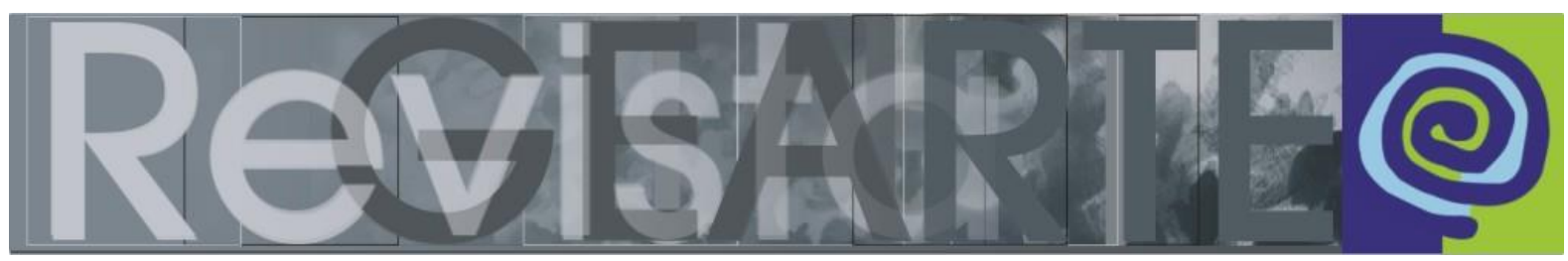

e-ISSN 2357-9854

\title{
Ensino de artes visuais e Políticas Públicas Educacionais
}

Provocar reflexões sobre a situação política no campo do ensino das Artes Visuais em função dos impactos de alterações recentes na legislação educacional brasileira é o propósito dos textos apresentados na Revista GEARTE sobre a temática Ensino de Artes Visuais e Políticas Públicas Educacionais.

A crise instalada na educação após as imposições do atual governo federal nos direciona a duas perspectivas de caminhos a seguir: a de perigo e a de oportunidade (RIOS, 2009). O perigo nos envolverá em atitudes negativas, ignorando as alternativas de superação. E a perspectiva de oportunidade nos remeterá à crítica.

Foi a perspectiva de oportunidade à crítica que nos motivou com todo o prazer a organizar esta coletânea de textos que discute tanto as pesquisas nacionais como as pesquisas internacionais, enfatizando a temática em foco. Cada um dos pesquisadores registrou de forma criteriosa e crítica os seus achados, revelando os cenários educacionais contemporâneos de suas pesquisas e instigando o leitor a compreender as tramas conduzidas e a necessidade de atitude para seguir em frente.

Concordamos com Rios (2009) ao afirmar que: "A atuação do educador não é o único fator que contribui, ou pode contribuir, para a melhoria da educação. Há fatores intra e extraescolares que interferem na prática dos educadores". (p. 71). Assim, perceber o que vem sendo conduzido de forma impositiva na área educacional exige de nós a crítica necessária para compreender os fenômenos que acontecem no dia a dia da prática educativa. "É no cotidiano de nossas práticas que estamos construindo a educação, que estamos fazendo a história da educação brasileira. (RIOS, 2009, p. 72)

As contribuições trazidas por António Nóvoa corroboram a análise do cenário autoritário/arbitrário que vivenciamos. Ao abordar dentre outros assuntos as reformas educacionais que estão ameaçando várias áreas de conhecimento, o autor é contundente ao ressaltar que: 
A ciência sem as artes, sem as humanidades, não é nada. É cega. É inútil. Transforma as sociedades do conhecimento em sociedades da ignorância. A universidade só existe se for capaz de acolher e de cultivar estas diferentes lógicas. É o que fazem as grandes universidades do mundo, que não se vergam aos discursos da moda, ao economicismo dominante, à confusão entre universidades e empresas. (NÓVOA, 2012, p. 642)

A área de conhecimento Arte, desde sua obrigatoriedade na educação básica, é um componente curricular que vem sofrendo ameaças constantes. A cada mudança na legislação, as incertezas sobre a sua presença no currículo escolar são evidenciadas nas discussões dos documentos advindos do Ministério da Educação (MEC), sendo necessária a vigília constante por parte dos envolvidos com a área, tanto das escolas como das Instituições de Ensino Superior que formam os professores para atuar na Educação Básica.

A Arte na Educação continua no centro do debate político pela sua fundamental importância na educação básica. Garantir o conhecimento artístico/estético/cultural na escola é nosso compromisso - assumido de forma individual e coletiva. E defender a presença das artes no currículo é nosso direito e dever.

Outra reflexão de Nóvoa, e que consideramos ser relevante em função das questões levantadas nos artigos desta seção temática, diz respeito às sugestões direcionadas aos dirigentes das universidades públicas brasileiras.

E preciso ser capaz de manter uma tensão inovadora entre a democratização do ensino superior (ao nível da graduação) e programas de formação avançada e de pesquisa audaciosos (ao nível da pós-graduação). Nem sempre é fácil, mas decisivo. (NÓVOA, 2012, p. 644)

Nóvoa nos inspira, neste momento crucial de desmandos nas políticas públicas, a afirmar a autonomia das instituições e combater diariamente todas as formas de ingerência, de burocratização, de asfixia das instituições visando garantir a liberdade acadêmica.

Assim, cientes das relações de poder subjacentes às reformas educacionais e com o intuito de fortalecer os debates no campo das Artes Visuais, apresentamos os textos da seção temática deste número da Revista GEARTE. 
Dois artigos internacionais analisam aspectos das políticas públicas para o ensino das artes no Chile, desenvolvidas no contexto da reforma educativa atualmente em implementação naquele país. Os autores nos oferecem, oportunamente, ensejo para reflexões sobre nosso próprio momento de implementação de políticas públicas educacionais para as artes. Enquanto estamos lutando para garantir a presença das artes na educação básica, no Chile há pelo menos duas artes (artes visuais e a música) como disciplinas obrigatórias em todos os níveis do que denominamos, aqui, de educação básica. A leitura desses artigos poderá enriquecer as nossas discussões e ampliar as possibilidades de rever os caminhos de implementação do componente curricular Arte na Base Nacional Comum Curricular (BNCC) considerando os exemplos que se aproximam da realidade brasileira.

No primeiro artigo - La enseñanza de las artes en la educación chilena: Plan Nacional de Artes en Educación (2015-2018), Dora Águila (Corporación Cultural Educarte Chile/COEDUCARTE, Santiago, Chile) - comenta a Lei Geral de Educação e, por consequência, as Bases Curriculares e o Plano Nacional de Artes na Educação, detalhando cada um dos seus cinco eixos transversais, seus objetivos e linhas de ação. A autora demonstra preocupação quanto ao impacto que as futuras políticas culturais poderão ter na educação chilena e, também, quanto à ação dos órgãos públicos federais em relação ao patrimônio artístico e cultural na educação formal. Por fim, pergunta: o que acontecerá com o Plano Nacional de Artes na Educação 2015-2018?

No segundo artigo - Do que falamos quando falamos de uma educação artística de qualidade: o caso chileno - Leonardo Verde Charréu e Madalena Campos Ghira (ambos da Escola Superior de Educação do Instituto Politécnico de Lisboa, Portugal) analisam o primeiro Caderno de uma série de cinco, publicados pelo Conselho Nacional da Cultura e das Artes do Chile. No Caderno analisado - que apresenta ferramentas metodológicas e conceituais para subsidiar projetos educacionais visando o acesso à cultura e às artes para todas as crianças e jovens chilenos - os autores enfocam a intencionalidade educativa da iniciativa política, especialmente a qualidade da educação em artes e sua contribuição à educação em geral. 
Já os artigos nacionais vão abordar assuntos que perpassam questões relativas ao ensino/aprendizagem, formação docente, currículo, BNCC, dentre outros. Inicialmente, no artigo Docência em Arte no contexto da BNCC: é preciso reinventar o ensino/aprendizagem em Arte? Lucia Gouvêa Pimentel (Universidade Federal de Minas Gerais, Brasil) e Ana Del Tabor Vasconcelos Magalhães (Universidade Federal do Pará, Brasil) discutem sobre a conjuntura das políticas públicas que incidem no processo das reformas curriculares que afetam o ensino/aprendizagem, a formação docente e o consequente exercício/atuação no componente curricular Arte. As autoras analisam os possíveis entraves na implementação da Base Nacional Comum Curricular/ Arte para Educação Infantil e Ensino Fundamental em 2017, e as interpretações que surgem sobre a BNCC/Arte para o Ensino Médio em 2018 (em fase de discussão), com ênfase para as Artes Visuais.

No artigo Uma cartografia sobre o Ensino das Artes Visuais na BNCC entre 20142018, de Maria Emilia Sardelich (Universidade Federal da Paraiba, Brasil) e Guilherme Panho (Universidade Federal de Pernambuco/Universidade Federal da Paraíba, Brasil), é apresentada uma cartografia sobre o Ensino das Artes Visuais na Base Nacional Comum Curricular (BNCC), entre 2014 e 2018. Destacam a desvalorização da Arte nessa política curricular frente à já conquistada demarcação como conhecimento em políticas anteriores e os resultados que apontam para uma ausência de dissertações e teses que discutam essa política curricular para o Ensino das Artes Visuais.

Em Para onde caminha o ensino das Artes Visuais? de autoria de Sonia Tramujas Vasconcellos (Universidade Estadual do Paraná, Brasil), Karine Storck (Universidade Federal do Rio Grande do Sul, Brasil) e Daniel Bruno Momoli (Universidade do Alto Vale do Rio do Peixe, Brasil), os autores analisam a área de arte no contexto da Base Nacional Comum Curricular e da Reforma do Ensino Médio. Refletem sobre as mudanças ocorridas no cenário educacional para situar e ampliar as discussões sobre a concepção de ensino e aprendizagem presente nesses documentos e que adentra os espaços escolares e a formação docente em Arte.

No artigo Juntos ou Separados: a busca pelo associativismo e o caso APAEP e APROAP, Luciano Parreira Buchmann (Universidade do Estado do Paraná, Brasil) e 
Luzia Aparecida Ferreira-Lia (Universidade Federal do Paraná, Brasil analisam e situam o associativismo no âmbito amplo das políticas públicas educacionais brasileiras e, mais especificamente, relacionado a duas entidades de classe do Paraná: A Associação dos Profissionais em Arte-educação do Paraná (APAEP) e a Associação dos Professores de Arte do Paraná (APROAP). Analisam a implementação da Base Nacional Comum Curricular-BNCC e da Reforma do Ensino Médio em relação aos efeitos da ação do coletivo das entidades nessa implementação.

No artigo Observatório da formação de professores de Artes Visuais: uma análise à luz das políticas vigentes, as professoras da Universidade do Estado de Santa Catarina, Brasil: Maria Cristina da Rosa Fonseca da Silva, Valéria Metroski de Alvarenga e Claudia Carnevskis discutem os resultados de um estudo realizado pelo projeto em rede Observatório da Formação de Professores no Âmbito do Ensino de Artes: estudos comparados entre Brasil e Argentina. As autoras presentam uma análise comparativa entre licenciaturas em Artes Visuais da Região Norte e da Região Sul do Brasil à luz das políticas públicas neoliberais vigentes e dos processos de expansão universitária. Concluem que os aspectos culturais regionais têm pouco espaço, o que favorece a uniformização da atuação docente, a precarização profissional dos docentes e, assim, a gradativa perda de seu papel como intelectual transformador.

O artigo Ensino de cinema na educação básica: aspectos legais de Diogo José de Moraes Lopes Barbosa (Universidade Federal da Paraíba, Brasil) e Guilherme Barbosa Schulze (Universidade Federal da Paraíba, Brasil) discute sobre a presença do cinema na escola de educação básica e enfatiza as formas de contemplar o cinema como uma linguagem artística. Os autores destacam que o cinema pode ser visto na escola a partir da Lei no13.006 de 2014, que institui a exibição de pelos menos duas horas de filmes nacionais por mês. Concluem que a arte cinematográfica é necessária do ponto de vista pedagógico para o crescimento do educando e que é importante ser inserida na escola.

Em Currículo como possibilidade de formação docente em arte: um olhar sobre a rede pública estadual paulista, Maristela Sanches Rodrigues (Instituto Federal de São Paulo, Brasil) com base em pesquisa realizada com professoras/es de Arte da rede 
pública estadual paulista (2012-2016), traz reflexões sobre encontros e desencontros entre as concepções formativas dessas/es professoras/es e as concepções trazidas pelo Currículo de Arte oficial de São Paulo (2008-atual), objetivando compreender como estava se dando o envolvimento das/os professoras/es de Arte da rede pública estadual paulista com o Currículo. As concepções de arte, de acesso à arte, de ensino de arte e de currículo de Arte, são categorias analisadas com 15 professoras/es de Arte. Conclui que o Currículo de Arte de São Paulo é parte de um conjunto de medidas dessas políticas e a despeito de ter sido imposto e não proposto à rede pública, é um currículo condizente com paradigmas de ensino/aprendizagem da arte pós-modernos. No entanto, sua implantação não propiciou a cada professor/a construir o que aqui denominou de "intimidade com suas concepções formativas."

Consuelo Alcioni Borba Duarte Schlichta e Guilherme Gabriel Romanelli (ambos da Universidade Federal do Paraná, Brasil) juntamente com Mauren Teuber (Universidade Estadual do Paraná, Brasil), no artigo Livros didáticos para o ensino da arte: não peça a ele o que ele não pode te dar apresentam resultados de uma pesquisa desenvolvida pela colaboração de pesquisadores de três instituições do Paraná. Discutem sobre a recente presença do livro didático do componente curricular Arte no Brasil. Analisam e desvelam as concepções de arte e ensino subjacentes às duas coleções de livros didáticos para o componente curricular Arte aprovadas na edição do PNLD 2017, notadamente o entendimento e os usos dos conceitos de polivalência e transdisciplinaridade. Traçam um breve panorama histórico do ensino da arte no Brasil desde a LDB 5692/71 e apresentam dados sobre os programas do governo federal sobre a distribuição de livros didáticos às escolas públicas. Os autores propõem que tanto na formação inicial dos docentes em Arte como na sua formação continuada, haja espaço para discussão, estudo e avaliação sobre o livro didático, pois são eles os protagonistas desse debate.

Enfim, cada texto desta seção temática é um convite para juntos continuarmos as trocas de saberes no campo das Artes Visuais diante das atuais reformas - ou contrarreformas -, que sinalizam contradições entre o que é dito nos documentos oficiais do MEC e o que é praticado nas instâncias educacionais. Além disso, as políticas educacionais geradas no bojo dessas reformas podem gerar, dentre tantos 
prejuízos para a educação, a sua precarização, a desigualdade educacional e, por fim, maior desigualdade social.

Se as reformas educacionais são inevitáveis, precisamos fortalecer o debate crítico.

\author{
Maria Helena Wagner Rossi ${ }^{1}$ \\ (Universidade de Caxias do Sul - \\ UCS, Caxias do Sul/RS, Brasil)
}

Ana Del Tabor Vasconcelos Magalhães ${ }^{2}$

(Universidade Federal do Pará UFPA, Belém/PA, Brasil)

Organizadoras do presente número.

\title{
Referências
}

RIOS, Terezinha Azerêdo. Ética e competência. São Paulo: Cortez, 2009.

SANTOS, Lucíola Licínio de Castro Paixão. Entrevista com o Professor António Nóvoa. In: Educação \& Sociedade, Campinas, v. 33, n. 119, p. 633-645, abr.- jun. 2012. Disponível em: http://www.scielo.br/scielo.php?script=sci_issuetoc\&pid=0101-733020120002 e http://dx.doi.org/10.1590/S0101-73302012000200016. Acesso em: 22 ago. 2018.

1 Graduada em Licenciatura em Desenho e Plástica. Mestre e Doutora em Educação na Universidade Federal do Rio Grande do Sul. Professora Titular da Universidade de Caxias do Sul (UCS) no Curso de Artes Visuais. Professora de Arte aposentada da rede estadual de ensino do Rio Grande do Sul. Líder do Grupo Interdisciplinar Arte, Cultura e Patrimônio - CNPq/UCS e vice-líder do Grupo de Pesquisa em Educação e Arte (GEARTE) - CNPq/PPGEDU/UFRGS. É coordenadora do Comitê de Ética em Pesquisa da Universidade de Caxias do Sul. É membro do Conselho de Representantes da FAEB. Foi vice-presidente da FAEB (Federação de Arte-Educadores do Brasil no biênio 20142016). Tem publicado artigos em revistas e capítulos de livros sobre leitura de imagens e compreensão estético-visual. É autora do livro Imagens que falam: leitura da arte na escola, publicado pela Editora Mediação (5ª ed.: 2011; PNBE: 2011).

2 Doutoranda em Artes - Programa de Pós-Graduação em Artes da Escola de Belas Artes da Universidade Federal de Minas Gerais? Linha de Pesquisa Artes e Experiências Interartes na Educação. Mestre em Educação pela Universidade da Amazônia (UNAMA), Especialista em Ensino Superior pela União das Escolas Superiores do Pará (UNESPA), Docente Adjunto III, da Universidade Federal do Pará (UFPA), Cursos de Licenciatura em Artes Visuais e Pedagogia. Licenciada em Educação Artística-Artes Plásticas pela Universidade Federal do Pará, membro associado da Federação de Arte Educadores do Brasil-FAEB e do Conselho de Representantes da FAEB. Atualmente é Coordenadora de Estágio do Curso de Licenciatura Plena em Artes Visuais, professora supervisora dos Estágios em Ensino das Artes Visuais (Ensino Fundamental, Médio e em Espaços Culturais) e Professora do Cursos de Pedagogia (Disciplina Arte e Educação) e Curso de Licenciatura em Artes Visuais (PARFOR/UFPA). 